\title{
SENTIDOS DO SUICÍDIO PARA PROFISSIONAIS DE UM DISTRITO SANITÁRIO
}

Robertha Gabardo Stoppa

Ana Claudia Nunes de Souza Wanderbroocke

Universidade Tuiuti do Paraná
Recebido em: 21/07/2020

$1^{\text {a }}$ revisão em: 14/09/2021

Aceito em: 24/09/2021

\section{RESUMO}

Este estudo buscou compreender os sentidos atribuídos ao comportamento suicida por profissionais de um Distrito Sanitário de uma cidade do sul do Brasil. Participaram 15 profissionais, com diferentes formações, lotados em três pontos de atenção à saúde. Os dados foram coletados por meio de entrevistas semiestruturadas e submetidos à análise das práticas discursivas. Foram discutidos os sentidos: desamparo social, isolamento de idosos, vulnerabilidades dos adolescentes, dificuldades socioeconômicas e transtornos mentais. Os resultados indicaram o suicídio como um fenômeno que é atravessado por questões sociais e econômicas, geradoras de desamparo. Idosos e adolescentes foram descritos como os grupos etários mais vulneráveis. Em menor escala, o suicídio foi considerado como consequência de um transtorno mental e associado ao discurso psiquiátrico. Discute-se a necessidade de os profissionais que atuam no campo da saúde contribuírem para a promoção e o fortalecimento comunitário e estarem implicados tanto no desenvolvimento humano e social como atentos para os fatores geradores de sofrimento psíquico.

Palavras-chave: suicídio; sistemas locais de saúde; pessoal da saúde. 


\section{SUICIDE SENSES FOR PROFESSIONALS OF A SANITARY DISTRICT}

\section{ABSTRACT}

This study aimed to understand the senses attributed to suicidal behavior by professionals from a Sanitary District in a southern Brazilian city. 15 professionals with different trainings and from three health care points participated. Data were collected through semi-structured interviews and were analyzed by analysis of discursive practices. The following senses were discussed: social helplessness, elderly' isolation, adolescents' vulnerability, socioeconomic difficulties and mental disorders. The results indicated suicide as a phenomenon that is crossed by social and economic issues, generating helplessness. Elderly and adolescents were described as the most vulnerable age groups. On a smaller scale, suicide was attributed to the individual with mental disorder, contemplating the psychiatric discourse. It discusses the need to promote community strengthening and to be involved in both human and social development as well as to be attentive to the factors generating psychic suffering.

Keywords: suicide; local health systems; health personnel.

\section{SENTIDOS DEL SUICÍDIO PARA PROFESIONALES DE UN DISTRITO DE SALUD}

\section{RESUMEN}

Este estudio buscó comprender los sentidos atribuidos al comportamiento suicida por profesionales de un Distrito de Salud em una ciudad del sur del Brasil. 15 profesionales con diferentes formaciones y de tres puntos de atención de salud participaron. Los datos fueron recolectados a través de entrevistas semiestructuradas y sometidos a análisis de prácticas discursivas. Se discutieron los sentidos: impotencia social, aislamiento de los ancianos, la vulnerabilidad de los adolescentes, dificultades socioeconómicas y trastornos mentales. Los resultados indicaron el suicidio como un fenómeno superpuesto por cuestiones sociales y económicas, generando impotencia. Los ancianos y los adolescentes fueron descritos como los grupos de edad más vulnerables. Em menor medida, el suicidio se atribuyó al individuo con trastorno mental, contemplando el discurso psiquiátrico. Se discute la necesidad de promover el empoderamiento de la comunidad y participar en el desarrollo humano y social, así como estar atento a los factores que generan sufrimiento psicológico.

Palabras clave: suicidio; sistemas locales de salud; personal de salud. 


\section{INTRODUÇÃO}

O suicídio é um fenômeno humano complexo e de relevante impacto social. Somente no ano de 2012, foram registrados no mundo 804.000 suicídios, o que contabiliza 2.000 mortes por dia, e uma a cada 40 segundos. No mesmo ano, o Brasil foi considerado o oitavo país do mundo em números absolutos de suicídios. Com relação às tentativas de suicídio, estima-se que os números sejam até vinte vezes maiores.

Outro aspecto relevante para a análise do fenômeno é que a Organização Mundial da Saúde (OMS) considerou que os dados oficiais brasileiros estão subnotificados, ou seja, os registros não são fiéis à realidade (OMS, 2014). Seguindo orientações da OMS, no ano de 2006, o Ministério da Saúde (MS) instituiu as Diretrizes Nacionais para a Prevenção do Suicídio, sob a Portaria $n^{\circ}$ 1.876, visando implementar medidas de registros, bem como de prevenção em todo o território brasileiro (Ministério da Saúde, 2006).

Entre as terminologias para referenciar o suicídio, a OMS, define como 'comportamento suicida fatal', também chamado de 'suicídio completado' ou somente 'suicídio', os atos contra a própria vida que resultam em morte, e em 'comportamento suicida não-fatal' para aqueles que não resultam em morte, também chamados de 'tentativas de suicídio, parassuicídio ou autolesão deliberada'. Já 'ideias suicidas' é um termo utilizado quando há pensamentos em matar-se. A denominação 'comportamento suicida' engloba tanto os pensamentos, planejamentos, tentativas, como o ato em si (OMS, 2014).

No discurso da psiquiatria atual, o suicídio não pertence a uma categoria nosológica específica, pois não constitui uma doença. Contudo, a maior parte dos casos está relacionada com transtornos mentais, dentre os mais recorrentes estão o transtorno de humor (principalmente a depressão), os transtornos por uso de substâncias psicoativas, as esquizofrenias e os transtornos de personalidade (Bertolote, Mello-Santos e Botega, 2010). Os autores afirmam ainda que a presença de um transtorno mental é um dos mais importantes fatores de risco para o suicídio.

Com uma perspectiva mais abrangente, a OMS (2014) considera o suicídio como um fenômeno que apresenta várias causas subjacentes que interagem entre si, tais como fatores psiquiátricos, sociais, culturais, psicológicos, biológicos e fatores relacionados ao histórico de vida da pessoa. O suicídio, nesta perspectiva, é um fenômeno multicausal e complexo por apresentar inúmeras variáveis, razão que justifica diversos estudos em diferentes campos de saber. Além disso, a OMS (2014) situa o suicídio na atualidade como um grave problema de saúde pública, orientando os países-membros, dentre eles o Brasil, a implantar políticas públicas para a sua prevenção que foquem na sociedade e nos grupos ou indivíduos que apresentam comportamentos de riscos. 
Os profissionais do sistema público de saúde, ocupam posição privilegiada para acolher, dar suporte e direcionamento para pessoas com sofrimento psíquico e comportamento suicida. Para que isto ocorra, é necessário que sejam capacitados para o enfrentamento desse sério problema, técnica e sensivelmente, sendo agentes que possam desempenhar condutas efetivas no cuidado integral à saúde. A OMS (2014) afirma que as pessoas frequentemente emitem sinais que estão em sofrimento psíquico, o que aponta para a importância desses profissionais serem capacitados para perceber, proporcionar os cuidados e realizar as intervenções necessárias.

Um dos aspectos relevantes para a prática neste campo são os sentidos atribuídos ao comportamento suicida pelos profissionais, uma vez que os mesmos orientam as condutas, ampliando ou restringindo as possibilidades de ação em relação aos problemas identificados. Partindo-se da perspectiva construcionista social, os sentidos são estabelecidos com base em construções realizadas em um espaço intersubjetivo, pois a construção de um campo de significado decorre da inter-relação humana na linguagem. Dessa maneira, a realidade é definida pelos acordos narrativos coorganizados em conversações compartilhadas nos grupos sociais, em um dado momento histórico. Assim sendo, buscou-se estudar os sentidos atribuídos às experiências que derivam da própria prática social, apreendendo os processos pelos quais as pessoas descrevem, explicam e compreendem o mundo (Gergen, 2010) e, no caso da presente pesquisa, o comportamento suicida.

Stoppa, Wanderbroocke e Azevêdo (2020) realizaram revisão sistemática referente à produção nacional de artigos sobre os profissionais de saúde no atendimento à pessoa que realizou tentativa de suicídio. No referido estudo, identificaram escassa produção nacional realizada na atenção primária, assim como voltada para os profissionais da saúde e nenhum que tivesse um distrito sanitário como foco da investigação. Diante da escassez de pesquisas nessa área, este estudo tem como objetivo compreender os sentidos atribuídos ao comportamento suicida por profissionais de um Distrito Sanitário de uma cidade do sul do Brasil.

A busca por melhor compreender a temática implica em uma contínua atualização por meio de estudos que forneçam dados para o manejo do fenômeno. No caso da presente pesquisa, buscam-se dados que subsidiem propostas de ações efetivas entre profissionais e usuários do sistema público de saúde brasileiro.

\section{MÉTODO}

\section{PARTICIPANTES E LOCAL}


A pesquisa foi realizada em um Distrito Sanitário de uma cidade do sul do Brasil, em três pontos de atenção à saúde: uma Unidade Básica de Saúde (UBS), uma Unidade de Pronto Atendimento (UPA) e um Centro de Atenção Psicossocial (CAPS). A escolha do local foi sugerida por profissionais do Departamento de Saúde Mental da Secretaria Municipal de Saúde (SMS), pela razão de o comportamento suicida ser um fenômeno preocupante devido ao número de ocorrências nessa localidade.

Participaram dessa pesquisa 15 profissionais de saúde de diferentes categorias, sendo 4 enfermeiras, 2 psicólogas, 3 agentes comunitários de saúde, 1 assistente social, 2 terapeutas ocupacionais, 1 psiquiatra e 2 médicos generalistas, sendo 13 mulheres e dois homens. Os participantes tinham entre 24 e 58 anos, e o tempo de atuação profissional variou entre dois anos e 10 meses e 24 anos. Foi considerado como critério de inclusão já ter efetuado atendimento a usuários que realizaram tentativa(s) de suicídio no atual local de trabalho.

\section{INSTRUMENTO}

A coleta de dados foi realizada por meio de entrevista semiestruturada, no período entre junho a agosto de 2017, as quais foram gravadas em áudio e transcritas na íntegra. O roteiro previamente estabelecido continha questões relacionadas as ações desenvolvidas para a prevenção e atendimento ao usuário que realizou a tentativa, assim como as concepções que os profissionais tinham sobre o suicídio e suas dificuldades encontradas ao realizarem o atendimento.

\section{PROCEDIMENTOS DE COLETA DE DADOS}

O projeto de pesquisa foi aprovado pela Secretária Municipal de Saúde e por um Comitê de Ética em Pesquisas em Seres Humanos, tendo recebido parecer de aprovação sob o CAAE 53447715.10000.5529. Todos os princípios éticos foram respeitados ao longo da pesquisa conforme determina a Resolução n 466/12 do Conselho Nacional de Saúde

Após aprovações, realizou-se contato com os coordenadores da UBS, do CAPS e da UPA que indicaram os profissionais de saúde por atingirem o critério de seleção. O objetivo da pesquisa foi esclarecido e todos os contatados aceitaram participar. A partir do aceite, foram agendados o dia e a hora para a entrevista de forma a não interferir nas atividades profissionais. Antes do início das entrevistas, todos os participantes assinaram o Termo de Consentimento Livre e Esclarecido.

\section{ANÁLISE DE DADOS}

Para tratamento dos dados, foi utilizada a Análise das Práticas Discursivas, como proposto por Spink e Medrado (2013), por se entender que os discursos, conhecimento institucionalizado e compartilhado nas comunidades linguísticas, representam a linguagem em ação e, por sua via, produzem sentidos que conduzem posições nas interações sociais. O sentido produzido pelo discurso, ou 
seja, nos momentos ativos da linguagem, é resultado que foi tecido pelo coletivo contextualizado em um determinado momento histórico e cultural. Desse modo, a produção de sentido, como afirmam os autores, é um fenômeno sociolinguístico em razão de a linguagem ser uma prática social que é produto e produtora das ações.

Para a análise, realizou-se o Mapa de Associação de Ideias, que permite construir colunas com os sentidos que sistematizam as entrevistas. Neste artigo, foram discutidos os sentidos: desamparo social, isolamento de idosos, a vulnerabilidade dos adolescentes, dificuldades socioeconômicas e transtornos mentais. O Mapa inicia-se com a transcrição sequencial das entrevistas, seguido de um resumo no qual é elaborada uma síntese da fala de cada entrevistado obtendo, dessa maneira, uma visão do conjunto dos assuntos discutidos. Tais assuntos são transpostos nas colunas e realizada a análise, buscando a produção de sentidos dada pelos entrevistados, por meio de seus posicionamentos e repertórios linguísticos utilizados (Spink \& Medrado, 2013), definidos, portanto, a posteriori.

\section{RESULTADOS E DISCUSSÃO}

\section{DESAMPARO SOCIAL}

Entre as implicações contidas no comportamento suicida, os participantes fizeram referência ao sentimento de desamparo vivido na atualidade. A fragilidade nas relações sociais, a prevalência da individualidade e o tempo acelerado, foram alguns dos fatores trazidos pelos entrevistados: "A sociedade está perdendo a essência, os valores... estamos sem valores, suportes...sem suporte familiar, religioso. ... A sociedade cobra para sermos o máximo!" (P2, enfermeira, UPA). "É um problema de saúde pública! A nossa sociedade está muito assim... ' $O$ ' indivíduo... $A$ gente só trabalha e 'tá lá numa rotina bem estressante." (P4, enfermeira, CAPS) "Perdemos a noção do sagrado, tudo virou descartável, rápido, falta um cuidado." (P6, psicóloga, CAPS)

Os repertórios utilizados pelos participantes evidenciam elementos do discurso sobre a vida na contemporaneidade, tal como apresentada por Bauman (2009), que entende que a sociedade atual vivencia uma experiência de desamparo, seja pela ausência do "sagrado", do "cuidado" (P6, psicóloga, CAPS), pela perda da "essência e suporte familiar, religioso" (P2, enfermeira, UPA). Nesse sentido, entendem que a sociedade está promovendo um sentimento de desagregação e individualismo, que gera isolamento e sentimento de desproteção, portanto, riscos para o suicídio.

A experiência de desamparo, como um sentido atribuído ao suicídio na contemporaneidade, encontra respaldo na proposta de Silveira e Dias (2016) quanto à necessidade de se promover a participação social, o fortalecimento da comunidade e o exercício da cidadania. Sem um sistema que promova a saúde coletiva, não há saúde mental. Portanto, é preciso desenvolver ações coletivas 
para promover a participação comunitária nos processos de transformações necessárias, fortalecendo as organizações em rede, com as pessoas atuando como atores sociais.

\section{ISOLAMENTO DE IDOSOS}

Outra questão trazida pelos profissionais entrevistados que também denuncia uma fragilidade nas relações atuais refere-se às dificuldades de ordem familiar e social que culminam em suicídios de idosos. "Hoje as pessoas perderam a noção do que é ter uma família, não tem diálogo em casa. Também têm muitos idosos isolados, sabe? Têm muitos idosos sozinhos, perdidos... e os adolescentes estão perdidos também." (P7, agente comunitária, UBS) "Então a gente vê muito idoso que fica sozinho... então eles não têm muitos vínculos. Nossa sociedade de maneira em geral não se prepara para essa longevidade que está acontecendo, aí isso traz um monte de conflitos." (P1, enfermeira, UBS).

O suicídio entre a população idosa no Brasil é uma realidade preocupante, que deveria ocupar lugar de destaque nas questões públicas de saúde. Segundo a OMS (2014), no ano de 2012, a taxa de suicídio de pessoas acima de 70 anos foi de 9,8/100.000 habitantes, a maior entre as faixas etárias. Silva, Cardoso, Saraceno e Almeida (2015) realizaram uma pesquisa em diferentes localidades do país, na qual entrevistaram idosos com 60 anos ou mais que apresentavam histórico de comportamentos suicidas, com o objetivo de identificar quais as dificuldades encontradas que os desencadearam. Os entrevistados demostraram tristeza, sentimento de abandono, isolamento, incompreensão de seus desejos pelos familiares e a ausência de manifestações de afeto e respeito. Os achados dessa pesquisa vão ao encontro da fala do profissional P1 entrevistado:

A vida das pessoas é muito dinâmica, então eles [idosos] não têm muito vínculo... a gente já teve aqui no bairro, por exemplo, de um idoso que mora sozinho adoecer, aí você vai fazer uma busca pra alguém acompanhar, aí não tem familiar, aí não tem um amigo, que triste isso e a gente vê aí. (P1, enfermeira, UBS)

A falta de apoio familiar pode funcionar como um disparador para o comportamento suicida nos idosos, pelo motivo de as relações próximas estarem esvaziadas, tornando o ambiente familiar incoeso, sem amparo emocional e suporte adequado, desfazendo os elos que os mantêm dispostos à vida. Tal fator pode fragilizar os recursos internos, deixando-os mais vulneráveis ao adoecimento psíquico.

Silva et al. (2015) também apontaram o processo migratório como um fator que contribui para a vulnerabilidade dos idosos, pois tais processos são sentidos como perda. A velhice é um momento da vida em que lembranças do passado se tornam presentes, surgindo um sentimento de falta do que se distanciou, principalmente quando se está longe da terra natal ou do lugar onde a vida foi 
construída. Isso ocorre com mais força quando se sentem sozinhos e não há um apoio social presente. Este dado corrobora com a fala do profissional P1:

Têm idosos aqui que, por exemplo, tiveram uma infância lá no sítio, vieram pra cidade pros filhos ter uma condição melhor, só que os filhos casaram, criaram a sua estrutura familiar, e eles daí ficam sem ter aquela coisa que eles tinham lá da infância, aqui eles não conseguiram se adaptar totalmente nessa vida moderna, de uma grande metrópole sem autonomia de sair de casa, pegar um ônibus, pra caminhar, pra fazer compras (P1, enfermeira, UBS).

O aumento da longevidade precisa ser acompanhado pela melhoria ou manutenção da saúde e qualidade de vida (OMS, 2014). O envelhecimento da população demanda implementações de políticas públicas que possam garantir o acesso à saúde integral, seja física, social e mental. Deve-se, portanto, desenvolver meios e recursos para minimizar o sofrimento dos idosos proporcionando dignidade nessa etapa de suas vivências. A prevenção do suicídio entre os idosos deve considerar as fragilidades expostas, entre elas a falta de apoio entre familiares e os processos migratórios, desenvolvendo um constante enriquecimento dos elos família e comunidade, e aumentando o apoio social que fortalece as referências protetoras.

Importante destacar que os profissionais que comentaram sobre os suicídios entre a população idosa encontravam-se na UBS. Como já apontado, os idosos costumam consumar o suicídio completado, portanto, não é uma população que comumente ingressa na Rede de Apoio Psicossocial (RAPS) por efetuar uma tentativa de suicídio. Os idosos acabam sendo mais atendidos na UBS pelos riscos da depressão e outros fatores de vulnerabilidade, o que demonstra a importância da prevenção e promoção de saúde para essa população, tanto no que diz respeito ao suicídio quanto à saúde integral.

Embora se considere as limitações já mencionadas, a conexão social pode representar um fator de proteção, traçar efeitos positivos e alimentar o desejo de viver e é especialmente importante para compreender o fenômeno suicida no idoso. A ameaça ao sentimento de pertença é uma das causas para o surgimento da ideação suicida, portanto, torna-se especialmente importante para compreender o fenômeno e para, desta maneira, desenvolver estratégias de prevenção. Sousa, Perrelli e Botelho (2018) elencaram, a partir de uma revisão sistemática de estudos sobre suicídio em idosos, os fatores de risco deste segmento etário e entre eles consta a privação social. Assim sendo, é importante, por exemplo, que as UBSs realizem atividades que convoquem os idosos para a participação social. Realizar caminhadas semanais, atividades em grupo, oferecer um espaço de escuta para que possam falar sobre si, são exemplos de ações que enlaçam para a vida. 


\section{AS VULNERABILIDADES DO ADOLESCENTE}

Outro sentido atribuído às ocorrências de suicídio se relacionou às vulnerabilidades enfrentadas por adolescentes. Segue um apontamento realizado por uma profissional entrevistada sobre atendimento aos adolescentes que idealizaram ou realizaram uma tentativa de suicídio:

Adolescentes não têm necessariamente um desejo da morte morrida, mas um desejo de mostrar 'eu tô aqui', morrer algo, matar algo de uma dor, às vezes sem a noção que matando algo desse sofrimento ele vai junto, queria matar algo de uma dor, de um sofrimento, que nem tem muita clareza que vai morrer junto nisso (P5, psicóloga, NASF).

No que concerne a essa faixa etária, as tentativas de suicídio têm sido uma situação recorrente na atualidade, principalmente entre o sexo feminino. Contudo, quanto ao suicídio consumado, a porcentagem entre os adolescentes foi a mais baixa, o que demonstrou que são as tentativas de suicídio que prevalecem nos adolescentes. Diante disto, é importante relembrar que uma tentativa de suicídio e o suicídio consumado, embora próximos, ocorrem com características diferentes. Nas tentativas costuma-se usar métodos menos letais, o que facilita o socorro, e geralmente não há um preparo prévio, sendo atos mais impulsivos (OMS, 2014).

As tentativas sem o objetivo da busca efetiva da morte real, podem ser pensadas como um pedido de ajuda, como um apelo de um sofrimento que já atravessa o suportável, como uma mensagem que busca o olhar dos outros, para que percebam seus sofrimentos emocionais. Junto a isso, há uma ambiguidade no desejo de morrer, pois, o que a pessoa deseja é livrar-se de um sofrimento, sendo que nas fantasias, é recorrente encontrar a busca por uma 'nova vida'. Como o comportamento de autoagressão (e.g., automutilação) e as tentativas de suicídio são mais frequentes na adolescência do que o suicídio consumado, esses atos precisam ser compreendidos como fenômenos que denunciam as dificuldades pessoais/familiares/sociais e que podem estar deixando essa faixa etária vulnerável, assim como, fazendo com que os adolescentes recorram a um método agressivo para representar a intensidade de um sofrimento, ou para livrar-se dele (Cassorla, 1985).

Pesquisas realizadas entre adolescentes que apresentavam ideias suicidas, ou já haviam realizado tentativas de suicídio, apontaram como razões para tais atos os vínculos familiares fragilizados, choque entre os interesses e valores dentro da ordem familiar, conflitos relacionados à identidade sexual, rompimentos amorosos ou não correspondidos, bullying, exposição à violência, abuso de álcool e outras drogas, sintomas depressivos, solidão, dentre outros (Kuczynski, 2014; Moreira \& Bastos, 2015). 
Os jovens estão muito insatisfeitos, porque nada mais satisfaz eles, parece que é tudo muito rápido, logo se alcança e eles perdem o interesse. Os pais às vezes são muito ausentes e compensam às vezes com coisas materiais, né? Eu acho que eles sentem ... tipo ... um vazio ... (P9, agente comunitário, UBS). Vemos adolescente fazendo automutilação hoje, se cortam. Isso vem muito da estrutura familiar, vejo os vínculos muito fragilizado hoje, às vezes nem é negligência! É questão da dinâmica familiar, está tudo muito corrido hoje (P10, assistente social, CAPS).

Os pensamentos sobre a morte, inclusive a própria, são comuns na adolescência, não sendo considerados um comportamento de risco (Botega, 2015). Alguns fantasiam a sua morte, imaginando quem sentiria a sua falta, quais pessoas os amavam de verdade, ou quem iria chorar no seu velório. Os adolescentes, através dessas fantasias, ou mesmo com uma tentativa de suicídio, estão buscando respostas para o lugar que ocupam na vida das outras pessoas e qual o valor que eles têm para os outros (Cassorla, 1985). Essa afirmação vai ao encontro de uma descrição que uma profissional entrevistada expôs sobre uma tentativa de suicídio de uma adolescente:

Por exemplo, uma adolescente me falava assim, ela fez uma tentativa de suicídio e o que ela queria mesmo, de verdade, era ser uma mosquinha pra saber quem que ia chorar no enterro dela ... ela queria saber que lugar que ela tinha junto do outro, quem vai chorar por mim, quem vai sentir a minha falta, quem que vai ficar culpado, uma agressividade também porque não me amou como deveria, às vezes até uma agressividade, né? No adolescente eu escutava muito isso... (P5, psicóloga, NASF).

Contudo, quando esses pensamentos sobre a própria morte estão mais intensos e permanentes que o esperado para um adolescente, se faz necessária uma intervenção que busque prevenir uma tentativa de suicídio, que, por um risco mal calculado, pode acabar com um desfecho fatal. É preciso diferenciar as fantasias de morte, ditas esperadas, daquelas que sinalizam um perigo. Para tanto, os sinais que os adolescentes emitem devem ser observados pelos adultos de sua convivência (Botega, 2015).

Uma questão relatada por uma profissional entrevistada trouxe uma importante discussão sobre a relação dos adolescentes com as redes sociais.

Assim ... a gente atende muita criança, muito adolescente que passa muito tempo no celular, nas redes sociais. A gente que trabalha com adolescente percebe muito o efeito disso, o que que é o efeito de uma rede social e [o que é] adolescente com 
relações muito imaginarizadas, muita fantasia ... na rede é fácil lidar com a frustração, agora ali no dia a dia, você tem que exercitar a frustração, exercitar a relação, a resiliência, as situações, as dificuldades, esse exercício eu vejo que parece que tá ficando menos (P5, psicóloga, NASF).

A força do 'virtual' surge como uma saída para a ausência de referências na convivência real, próxima, e que exige resoluções. Os adolescentes na atualidade vivem relações virtuais, fazem amigos ou namorados/das por internet, mas, no encontro real, frente a frente, a insegurança surge, os desafios reais aparecem, mas não há encorajamento para a superação que os fariam caminhar para a vida adulta com maior preparo. Como aponta Silva (2008), o ato suicida é um gesto de comunicação dirigida para uma sociedade, é um ato que representa um rito de passagem na qual a pessoa tenta reintegrar-se como um novo membro, um novo personagem. $\mathrm{O}$ autor defende que o suicídio é um ato de comunicação, apesar de solitário, para uma sociedade que o impediu de comunicar-se de outras maneiras que não fosse através desse gesto.

A questão importante a refletir sobre o comportamento suicida dos adolescentes é pensar sobre o que estão querendo comunicar à sociedade com suas mortes e o que estão buscando nas tentativas de suicídio. Realizar a leitura psicossocial do comportamento suicida entre os adolescentes, fato de preocupação social, é importante para compreensão do fenômeno, pois ela nos encaminha para além de um ato que se encerra em si mesmo, mas estende-se para questões mais amplas que podem potencializar vulnerabilidades características da adolescência.

O relato de uma profissional entrevistada aponta para a importância de o meio escolar perceber quando um adolescente se encontra em risco, para que não ocorra um agravamento que o coloque em situação de maior vulnerabilidade.

O adolescente não chega na atenção primária, ele chega menos, mas quando ele chega, precisa correr, porque alguém traz, e quando não é nem alguém que traz que ele tem que vir sozinho tem que correr mais ainda. Quando o adolescente é escutado ele volta, ele vem, tudo o que tá em jogo é questão do manejo, forma da abordagem, forma de acolhida, conforme acolhe o adolescente ele volta ou ele não volta (P5, psicóloga, NASF).

Quando a entrevistada narra, "não chega na atenção primária, mas quando ele chega, precisa correr", aponta que ocorreram falhas anteriores de prevenção na territorialidade. Por exemplo, a escola é um ambiente favorável para desenvolver promoção da saúde e prevenção do suicídio (Antunes, 2019), lembrando que os demais setores precisam estar igualmente preparados para lidar com essa demanda entre os adolescentes, principalmente porque a sociedade tem vivido 
esse drama. Os profissionais do CAPS-I (infância), da mesma maneira, que atendem crianças e adolescentes até 18 anos com comprometimento em saúde mental, também estão vinculados a um ambiente favorável para mobilizar os recursos essenciais na prevenção do suicídio. Os profissionais da UBS, que estão próximos das famílias, precisam estar atentos e oferecer uma escuta qualificada, assim como os profissionais de uma UPA, que socorrem adolescentes com tentativas de suicídio, que eles possam realizar um atendimento humanizado, sem críticas ou julgamentos e que estejam sempre 'em prontidão' para oferecer apoio emocional, seja para o adolescente como para os familiares.

Os profissionais entrevistados mostraram-se sensíveis à vulnerabilidade que envolve os adolescentes atualmente, percebem os riscos e apontam, por meio dos repertórios linguísticos utilizados, o "desejo de matar uma dor" (P5, psicóloga, NASF); os "vínculos fragilizados" (P10, assistente social, UBS); a "ausência dos pais" (P9, agente comunitário, UBS); o "sentimento de vazio" (P9, agente comunitário, UBS); os "efeitos das redes sociais" (P5, psicóloga, NASF); ou a "falta de estrutura

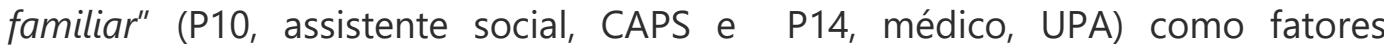
precipitantes para o comportamento suicida. Portanto, demonstram a compreensão de que é um momento de vida que necessita investimentos parentais eficazes na preparação para a vida adulta, e, na falt destes, os adolescentes mostram-se vulneráveis.

Neste sentido, os profissionais entrevistados percebem que há famílias que passam por consideráveis dificuldades, contudo, o olhar não pode ser de culpabilidade em relação aos pais, mas de alcançar que se os filhos estão cumprindo os cinquenta desafios da Baleia Azul (jogo que consiste em convocar adolescentes para desafios que culminam em um ato suicida e que estava em curso nas mídias na época da realização desta pesquisa), os pais estão realizando os 'cinquenta desafios da sobrevivência da era capitalista'. As famílias na atualidade sofrem os efeitos das configurações impostas pelas novas formas do mercado de trabalho, do declínio nos modelos de identificação, do hiperconsumismo e do individualismo, das relações 'virtuais', para citar alguns. As famílias não estão desvinculadas das relações sociais, portanto, há um movimento dialético que implica em reajustes históricos. Se há um discurso em atribuir culpa às famílias pelos conflitos dos adolescentes na atualidade, isso será um obstáculo em promover um cuidado de forma sistêmica. Como já afirmou Silva (2008), há um gesto de comunicação na tentativa de suicídio. Cabe aos profissionais aprimorarem a escuta para alcançar o que eles estão tentando transmitir e identificar as possíveis vulnerabiliades.

\section{DIFICULDADES SOCIOECONÔMICAS}

Os profissionais de saúde entrevistados também refletiram sobre o sentido do comportamento suicida atrelado à crise econômica vivenciada no país no momento da coleta de dados desta pesquisa: 
A gente tem uma carga de pessoas desempregadas, né? Então, com a crise no Brasil, por exemplo, né, desde 2015, eu acho que aumentou o número, pelo menos ao meu ver, de tentativas de suicídio. Aparece pra gente as pessoas muito desesperadas, que perderam o emprego, daí diversos outros problemas decorrentes disso (P12, terapeuta ocupacional, CAPS).

Ele se suicidou porque estava endividado, então hoje em dia, né, o que a gente vê é isso. Muitas pessoas estão se suicidando por causa de dívidas, parte pro desespero, né? (P8, agente comunitário, UBS).

Os autores portugueses Silva et al. (2015) realizaram um estudo reunindo evidências sobre o impacto da crise econômica na morbidade psiquiátrica, concluindo que fatores como o desemprego, empobrecimento, endividamento e perda de status socioeconômico estão associados ao agravamento de perturbações depressivas, perturbações de ansiedade, consumo de substâncias psicoativas e o suicídio. Apontam que as experiências anteriores de crises econômicas, tais como a Grande Depressão nos Estados Unidos da América (EUA) em 1929-1937, a recessão após o colapso da União Soviética no início dos anos 1990, e a crise do sudeste asiático de 1997, apresentam como consequências um aumento do suicídio e da mortalidade por abuso de álcool.

Os mesmos autores (Silva et al, 2015) também mencionam a crise econômica global, desencadeada a partir de 2008, com o colapso do crédito e do mercado imobiliário dos Estados Unidos. Tal crise provocou efeitos negativos na saúde mental em 54 países europeus e americanos, particularmente entre os homens. Em países com níveis mais elevados de perda de emprego, ocorreu um aumento no número de suicídios, assim como nos números relativos à depressão e outras perturbações psiquiátricas.

O impacto psicológico de estar desempregado, vivenciar uma mudança social que reduz a segurança financeira, sofrer sentimentos de estigmatização, vergonha, isolamento e humilhação por estar endividado/desempregado, são fatores desencadeantes para o adoecimento mental e para o comportamento suicida. Barnes et al. (2016) produziram uma pesquisa no Reino Unido, na qual entrevistaram 19 pessoas que realizaram uma tentativa de suicídio pelo motivo de estarem sofrendo severas dificuldades econômicas resultantes da recessão (desemprego, dívida, falência, entre outros). Os participantes também relataram sofrimento com outras questões, tais como, terem sofrido abusos, negligências, bullying, terem baixa autoestima, entre outras. A crise financeira advinda da recessão econômica foi o fator contribuinte final para a tentativa de suicídio. Reforçando, desta maneira, o que a OMS (2014) afirma sobre o suicídio sempre apresentar múltiplas causas, sendo que para compreender esse fenômeno é preciso o resgate da biografia juntamente com um olhar psicossocial, promovendo uma mediação entre os múltiplos fatores. 
O estudo realizado por Silva et al. (2015) conclui que após uma recessão os resultados em saúde podem variar em razão de dependerem das causas e contextos da crise, mas principalmente da resposta que o país oferta. É esperado que crises econômicas possam gerar consequências na saúde mental das pessoas, e é preciso ações políticas para minimizar os efeitos negativos. É importante que os cuidados em saúde mental sejam acessíveis e de qualidade, atendendo às necessidades da comunidade com soluções que se "adequem às mudanças sociais, laborais e de estatuto socioeconômico da população, que melhorem a detenção precoce dos problemas de saúde mental, da ideação suicida [...] e que deem particular atenção aos grupos mais vulneráveis e à prevenção" (p. 71).

Os profissionais de saúde entrevistados compreendem que a atual crise que o Brasil está enfrentando gera efeitos na saúde mental da comunidade, como narra o profissional P6 (psicóloga, CAPS), "a pessoa perde o lugar, perde o papel que ela exercia, perde o sentido da vida", no entanto, eles próprios também se sentem vulneráveis, como desabafa a entrevistada P3 (enfermeira, UPA): "ultimamente o clima aqui está muito pesado [...], tem que pensar em alguma coisa porque a demanda está aumentando muito!".

Importante ressaltar que políticas concretas devem ser efetuadas nos diversos setores, não somente no âmbito da saúde mental, mas também em programas ativos de reinserção no mercado de trabalho, apoio psicológico aos grupos de pessoas vulneráveis (desempregados, endividados, crianças, idosos, portadores de doenças crônicas, etc.), programas de apoio financeiro às famílias, programas de alívio e controle das dívidas e acesso a microcréditos, assim como intervenções de combate à exclusão econômica, promovendo a participação social.

\section{TRANSTORNOS MENTAIS}

Por fim, alguns profissionais relacionaram o comportamento suicida, seja no ato consumado ou na tentativa, com uma questão diretamente implicada com transtornos mentais, como apontam P3 (enfermeira, UPA) e P9 (agente comunitário, UBS):

É transtorno mesmo, a pessoa já nasce assim. Eu trato assim como uma pessoa doente... a gente fica com pena, com dó né? Mas você sabe que é uma pessoa doente. Doente, mas é de cabeça, né, mental. É da psiquiatria penso que é assim... da cabeça (P3, enfermeira, UPA).

O suicídio é mais nessas pessoas, depressivas, bipolares. São pessoas difíceis de lidar! (P9, agente comunitário, UBS).

Em estudo do fenômeno suicida, Netto (2013) aponta para os excessos de discursos com abordagens patológicas, e muitas vezes biológicas, que 
escamoteiam as questões sociais tão importantes para a compreensão do ato suicida. Contesta publicações que afirmam que cerca de $90 \%$ dos casos de suicídio e $40 \%$ das tentativas, estão associadas aos transtornos mentais, principalmente à depressão e ao abuso de álcool e outras drogas. O autor argumenta que esses dados vão na contramão da definição do suicídio como um ato complexo e multideterminado, justamente por restringirem o fenômeno quase que totalmente às questões de ordem orgânica e psíquica. Chama a atenção para que não se perca de vista as profundas raízes sociais no fenômeno suicida, pois, desta maneira, corre-se o risco de abordar o tema de forma individualizante, enquanto trata-se de um problema que tem também implicações sociais (Netto, 2013).

Neste sentido, não se pretende ignorar que transtornos mentais apresentam risco considerável para o suicídio. Cescon, Capozzolo e Lima (2018), em estudo realizado em um CAPS III em um município de São Paulo encontraram que os profissionais relacionavam o suicídio tanto ao sofrimento por questões psicossociais como transtorno psiquiátrico, porém com maior oferta de medicalização do que escuta. Fato que merece ser questionado, uma vez que é imprescindível o cuidado com as pessoas acometidas com depressão, bipolaridade, dentre outras. Contudo, para uma compreensão mais próxima das razões que determinadas comunidades/sociedades apresentam taxas preocupantes de comportamento suicida, é imperioso ampliar o olhar para as questões psicossociais. Se estamos vivendo em uma sociedade com índices de depressão alarmantes, é preciso perguntar o porquê que isto está ocorrendo. Além disso, o suicídio é muito complexo para ser explicado em uma relação inequívoca entre causa e efeito, e é um equívoco cometer generalizações. As taxas de suicídio de uma grande metrópole podem ocorrer por razões diferentes de uma cidade do interior, e por motivos diferentes ainda nos grupos indígenas, apesar de nesses lugares a depressão poder aparecer como um fator desencadeante. O suicídio não pode ser abordado somente como uma questão individual, pois está envolto pelas relações sociais.

\section{CONSIDERAÇÕES FINAIS}

Este estudo buscou compreender os sentidos atribuídos ao comportamento suicida por profissionais de um Distrito Sanitário de uma cidade do sul do Brasil. As falas dos profissionais de saúde entrevistados apontaram para questões sociais contemporâneas como fatores contributivos, bem como para os grupos etários mais vulneráveis.

O suicídio foi visto por psicólogos, psiquiatras, enfermeiros, médicos, terapeutas ocupacionais e agentes comunitários de saúde que atuavam em UBS, CAPS e UPA, principalmente como um fenômeno atravessado por questões sociais e econômicas, geradoras de um sentimento de desamparo. Em menor escala, o suicídio foi atribuído ao indivíduo com transtorno mental, contemplando o discurso psiquiátrico. Idosos e adolescentes foram descritos como os grupos 
etários mais vulneráveis, o primeiro pelo isolamento social e o segundo, por conflitos internos e relacionais. Portanto, os dados indicam que, por um lado os profissionais estão atentos e compreendem o suicídio em sua complexidade e multideterminação. Por outro lado, os sentidos produzidos ainda tendem a uma estratificação, refletindo o discurso dominante da ciência, centrado na classificação etária e psiquiátrica.

Cabe reafirmar, frente aos dados obtidos, a complexidade do fenômeno e que a sua prevenção e abordagem não podem ser circunscritas a faixas etárias e condições prévias de saúde e de vida. Ao mesmo tempo em que a identificação de fatores de risco facilita a aproximação e deve orientar as ações em saúde, também pode tirar a atenção de usuários em situação de vulnerabilidade, fragilizando a integralidade nas intervenções em saúde.

Neste sentido, a abordagem ao comportamento suicida perpassa por questões abrangentes, das macro às microssociais, tais como, o modo de vida das pessoas, suas relações com o trabalho, com a família e com a comunidade. É uma questão de saúde pública, porque aponta para as configurações da sociedade atual e suas vulnerabilidades. Investir em saúde mental, no campo da saúde pública, demanda além da identificação dos fatores de risco, a criação de espaços para a elaboração de saberes e recursos para propiciar mudanças necessárias em seu entorno. Significa, em outras palavras, promover o fortalecimento comunitário e estar implicado tanto no desenvolvimento humano e social, como atento para os fatores geradores de sofrimento psíquico, independentemente da faixa etária.

Como esta pesquisa se limitou aos relatos de profissionais de um distrito sanitário, sugere-se que outros pesquisadores deem segmento à busca dos sentidos atribuídos ao comportamento suicida em outros contextos de saúde, como nos hospitais, a fim de que se possa refletir e propor ações efetivas para prevenir e atender pessoas em sofrimento psíquico.

\section{REFERÊNCIAS}

Antunes, M. C. (2019). Projeto viva vida: Promoção de saúde e prevenção do suicídio. In A. C. N. S Wanderbroocke, \& M. S. L. Dias (Eds.), Suicídio: Abordagens psicossociais para a prevenção (pp. 95-109). Curitiba, PR: Juruá.

Barnes, M. C., Gunnell, D., Davies, R., Hawton, K., Kapur, N., Potokar, J., \& Donavan, J. L. (2016). Understanding vulnerability to self-harm in times of economic hardship and austerity: A qualitative study. B. M. J. Open, 6, Article e010131. http://dx.doi.org/10.1136/bmjopen2015-010131

Bauman, Z. (2009). Vida líquida. (2 ${ }^{\mathrm{a}}$ ed.). Rio de Janeiro, RJ: Zahar.

Bertolote, J. M., Mello-Santos C., \& Botega, N. J. (2010). Detecção do risco de suicídio nos serviços de emergência psiquiátrica. Revista Brasileira de Psiquiatria, 32(Suppl. 2), S87-S95. https://doi.org/10.1590/S1516-44462010000600005

Botega, N. J. (2015). Crise suicida avaliação e manejo. Porto Alegre, RS: Artmed.

Cassorla, R. M. S. (1985). O que é suicídio. São Paulo, SP: Brasiliense.

Cescon, L. F., Capozzolo, A. A., \& Lima, L.C. (2018). Aproximações e distanciamentos ao suicídio: Analisadores de um serviço de atenção psicossocial. Rev. Saúde e Sociedade, 27(1), 185200. https://doi.org/10.1590/S0104-12902018170376

Gergen, K. J. (2010). Construcionismo social um convite ao diálogo. Rio de Janeiro, RJ: Instituto Noos. 
Kuczynski, E. (2014). Suicídio na infância e adolescência. Psicologia USP, 25(3), 246-252. https://doi.org/10.1590/0103-6564D20140005

Ministério da Saúde. (2006). Portaria n 1.876, de 14 de agosto de 2006. Institui Diretrizes Nacionais para Prevenção do Suicídio. Brasília, DF: Ministério da Saúde.

Moreira, L. C. O., \& Bastos, P. R. H. O. (2015). Prevalência e fatores associados à ideação suicida na adolescência: Revisão de literatura. Revista Quadrimestral da Associação Brasileira de Psicologia Escolar e Educacional, 19(3), 445-453. https://doi.org/10.1590/21753539/2015/0193857

Netto, N. B. (2013). Suicídio e os desafios para a psicologia. Brasília, DF: CFP.

Organização Mundial de Saúde. (2014). Prevención del suicídio: um imperativo global. Genebra: Organização Mundial da Saúde.

Silva, M., Cardoso, G., Saraceno, B., \& Almeida, J. C. (2015). A saúde mental e a crise económica. In P. Santana (Ed.), Território e saúde mental em tempos de crise (pp. 64-77). Coimbra: Imprensa da Universidade de Coimbra.

Silva, M. M. (2008). Suicídio: Trama da comunicação. São Paulo, SP: Scortecci.

Silva, R. M., Mangas, R. M. N., Figueiredo, A. E. B., Vieira, L. J. E. S., Sousa, G. S., Cavalcanti, A. M. T. S., \& Apolinário, A. V. S. (2015). Influências dos problemas e conflitos familiares nas ideações e tentativas de suicídio de pessoas idosas. Ciência \& Saúde Coletiva, 20(6), 1703-1710. https://doi.org/10.1590/1413-81232015206.01952015

Silveira, K. G. B., \& Dias, M. S. L. (2016). As categorias da psicologia social comunitária como dispositivo para a construção das práticas no SUS. Revista Psicologia e Saúde, 8(1), 7-13. http://dx.doi.org/10.20435/2177093X2016106

Sousa, G. S., Perrelli, J. G. A., \& Botelho, E. S. (2018). Diagnóstico de enfermagem Risco de suicídio em idosos: Revisão integrativa. Revista Gaúcha de Enfermagem, 39, Artigo e2017-0120. https://doi.org/10.1590/1983-1447.2018.2017-0120

Spink, M. J., \& Medrado, B. (2013). Produção de sentidos no cotidiano: Uma abordagem teóricometodológica para análise das práticas discursivas. In M. J. Spink (Ed.), Práticas discursivas e produção de sentidos no cotidiano. Aproximações teóricas e metodológicas (pp. 22-41). Rio de Janeiro, RJ: Centro Edelstein de Pesquisas Sociais.

Stoppa, R.G., Wanderbroocke, A.C.N.S., \& Azevêdo, A. V. (2020). Profissionais de saúde no atendimento ao usuário com comportamento suicida no Brasil: Revisão sistemática. Rev. Psicologia e Saúde, 12(4): 65-80. http://dx.doi.org/10.20435/pssa.vi.1065

\section{SOBRE OS AUTORES}

Robertha Gabardo Stoppa é Psicóloga formada pela PUC-PR, mestre em Psicologia pela Universidade Tuiuti do Paraná.

E-mail: robertha.gabardo.stoppa@hotmail.com

(1) https://orcid.org/0000-0002-3991-7102

Ana Claudia N.S. Wanderbroocke é Psicóloga formada pela UFPR. Doutora em Psicologia pela UFSC, Docente do Programa de Pós-Graduação em Psicologia da Universidade Tuiuti do Paraná. E-mail: ana.wanderbroocke@utp.br

(6) https://orcid.org/0000-0002-2876-5326 